\title{
Holoprosencephaly and preaxial polydactyly associated with a 1.24 Mb duplication encompassing FBXW11 at $5 q 35.1$
}

\author{
David A. Koolen · Jos Herbergs · Joris A. Veltman · Rolph Pfundt • \\ Hans van Bokhoven - Hans Stroink · Erik A. Sistermans • \\ Han G. Brunner · Ad Geurts van Kessel · Bert B. A. de Vries
}

Received: 22 March 2006/ Accepted: 2 May 2006/Published online: 25 July 2006

(C) The Japan Society of Human Genetics and Springer-Verlag 2006

\begin{abstract}
Holoprosencephaly (HPE) is the most common developmental defect affecting the forebrain and midface in humans. The aetiology of HPE is highly heterogeneous and includes both environmental and genetic factors. Here we report on a boy with mild mental retardation, lobar HPE, epilepsy, mild pyramidal syndrome of the legs, ventricular septal defect, vesicoureteral reflux, preaxial polydactyly, and facial dysmorphisms. Genome-wide tiling path resolution array based comparative genomic hybridisation (array $\mathrm{CGH}$ ) revealed a de novo copy-number gain at 5q35.1 of $1.24 \mathrm{Mb}$. Additional multiplex ligation-dependent probe amplification screening of a cohort of 31 patients with HPE for copy-number changes at the 5q35.1 locus did not reveal any additional genomic anomalies. This report defines a novel $1.24 \mathrm{Mb}$ critical interval for HPE and preaxial polydactyly at $5 \mathrm{q} 35.1$. The duplicated re-
\end{abstract}

Electronic Supplementary Material Supplementary material is available to authorised users in the online version of this article at http://dx.doi.org/10.1007/s10038-006-0010-8.

D. A. Koolen · J. A. Veltman · R. Pfundt

H. van Bokhoven - E. A. Sistermans · H. G. Brunner ·

A. Geurts van Kessel · B. B. A. de Vries $(\square)$

Department of Human Genetics,

Radboud University Nijmegen Medical Centre,

9101, 6500 HB Nijmegen, The Netherlands

e-mail: b.devries@antrg.umcn.nl

J. Herbergs

Department of Clinical Genetics, Academic Hospital,

Maastricht, The Netherlands

H. Stroink

Department of Neurology,

St. Elisabeth and TweeSteden Hospital,

Tilburg, The Netherlands gion encompasses seven genes: RANBP17, TLX3, NPM1, FGF18, FBXW11, STK10, and DC-UbP. Since $F B X W 11$ is relatively highly expressed in fetal brain and is directly involved in proteolytic processing of GLI3, we propose $F B X W 11$ as the most likely candidate gene for the HPE and prexial polydactyly phenotype. Additional research is needed to further establish the role of genes from the $5 \mathrm{q} 35.1$ region in brain and limb development and to determine the prevalence of copy number gain in the 5q35.1 region among HPE patients.

Keywords Array CGH $\cdot B T R C P \cdot F B X W 11$. FGF18 · Holoprosencephaly · Microduplication · $5 \mathrm{q} 35.1$

\section{Introduction}

Holoprosencephaly (HPE [MIM 236100]) is the most common developmental defect in humans affecting the forebrain and midface. The aetiology of HPE is highly heterogeneous and includes both environmental and genetic factors (Wallis and Muenke 2000). At least 12 different genetic loci have been associated with HPE (Dubourg et al. 2004). Causative mutations have mainly been identified in four genes: Sonic Hedgehog (SHH MIM:600725) at 7q36, ZIC2 (MIM:603073) at 13q32, SIX3 (MIM:603714) at 2p21, and transforming growth factor-beta-induced factor (TGIF MIM:602630) at 18p11.3 (Dubourg et al. 2004). Recently, Bendavid et al. (2006) found microdeletions encompassing these four genes in 16 out of 339 severe HPE cases $(4.7 \%)$. Therefore, microdeletion of these genes may contribute to the aetiology of HPE. Here 
we report on the identification of a de novo microduplication at 5q35.1 in a patient with lobar HPE and preaxial polydactyly. The microduplication defines a novel $1.24 \mathrm{Mb}$ critical interval for HPE and preaxial polydactyly on human chromosome 5q35.1.

\section{Materials and methods}

\section{Clinical report of the index patient}

The 19-year-old patient was referred to our department in Nijmegen for genetic counselling. He presented with mild mental retardation, delayed motor development, and a mild pyramidal syndrome. He was born after an uncomplicated pregnancy and delivery. Right preaxial polydactyly (digitus minimus) was noted, as well as an asymmetric crying face due to aplasia of the right musculus anguli oris. The patient had a ventricular septal defect and at 5 years of age, he was operated on because of vesicoureteral reflux. He has had infrequent tonic-clonic seizures since the age of 6 years. Magnetic resonance imaging of the cerebrum revealed a lobar HPE (see Fig. 1). At 15 years of age, he was small (height $157 \mathrm{~cm} ;<-2 \mathrm{SD}$ ) with a relatively large occipitofrontal circumference (OFC) of $57 \mathrm{~cm}$ (+1SD). In addition, he exhibited an asymmetric face (left < right), synophrys, up-slanting palpebral fissures, finger-like thumbs, remnants of the polydactyly near the right thumb, and sandal gaps between the first and second toes (see Fig. 2). In addition, the tendon reflexes were brisk with a clonus of the ankles and two Babinski signs. Routine chromosome analysis was normal and subtelomeric multiplex ligation-dependent probe amplification (MLPA) failed to reveal any anomalies (SALSA MLPA kit P036, MRC Holland,
Amsterdam, The Netherlands). Subsequently, the patient was included in a series of 100 mentally retarded patients tested by genome-wide tiling path resolution array-based comparative genomic hybridisation (array CGH) (De Vries et al. 2005).

Array CGH and confirmation

The proband was tested for submicroscopic aberrations using array $\mathrm{CGH}$. A tiling-resolution microarray consisting of 32.477 BAC clones, covering the entire human genome, was used. Microarray preparation, hybridisation, and data analysis, were described in detail previously (De Vries et al. 2005). Genomic DNA from the patient was hybridised in duplicate with dyeswap against a sex-mismatched reference pool. Parental samples were hybridised once against the same reference pool. Copy-number detection was performed automatically using a Hidden Markov model as described previously (De Vries et al. 2005). The array CGH results were confirmed using MLPA (Schouten et al. 2002). Fluorescence in situ hybridisation (FISH) using BAC clones also present on the array (RP11768O14, CTD-2315O11, RP11-413I18, RP11-575K18) was used to determine the location of the aberration in the genome.

Screening for copy-number changes at $5 \mathrm{q} 35$ among HPE patients using MLPA

In total, 31 DNA samples from patients with HPE were tested for copy-number changes in the $5 \mathrm{q} 35.1$ region using MLPA. Of these, 27 had HPE only and had previously been tested by sequencing analysis for mutations in SHH, ZIC2, SIX3, and TGIF. The remaining four patients both suffered from HPE and

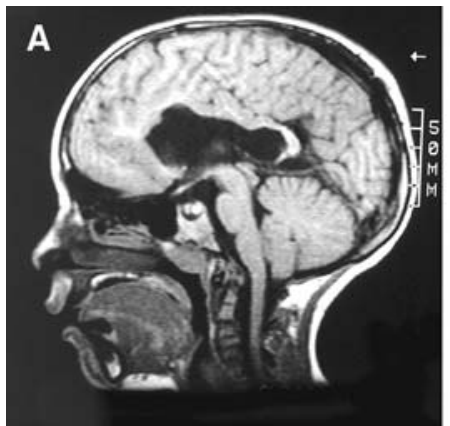

Fig. 1a-c T1-weighted magnetic resonance imaging (MRI) of the cerebrum at 6 years of age. The sagital T1-weighted image (a) shows the absence of the anterior part of the corpus callosum, characteristic of holoprosencephaly (HPE). Note that the frontal lobes are fused. The coronal T1-weighted image (b) and axial
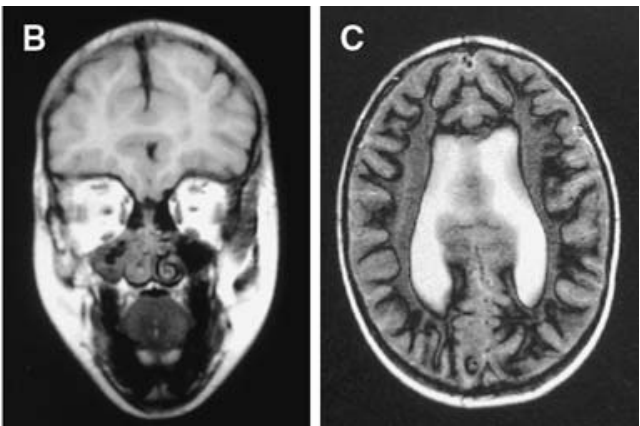

inversion recovery image (c) reveal that the interhemisperic fissure is absent in the frontal region, the frontal lobes are basely fused, and the grey matter is continuous between both the left and right hemispheres 
Fig. 2a-g Patient at 15 years of age. Note the small height: $1.57 \mathrm{~m}(-2 \mathrm{SD})$ with a relatively large skull $(+1 \mathrm{SD})$, synophrys, up-slanting palpebral fissures, the asymmetric face $(\mathbf{a}-\mathbf{c})$, the finger-like thumbs $(\mathbf{d}, \mathbf{e})$, the remnants of the polydactyly near the right thumb (f), and the sandal gap between first and second toes $(\mathbf{g})$
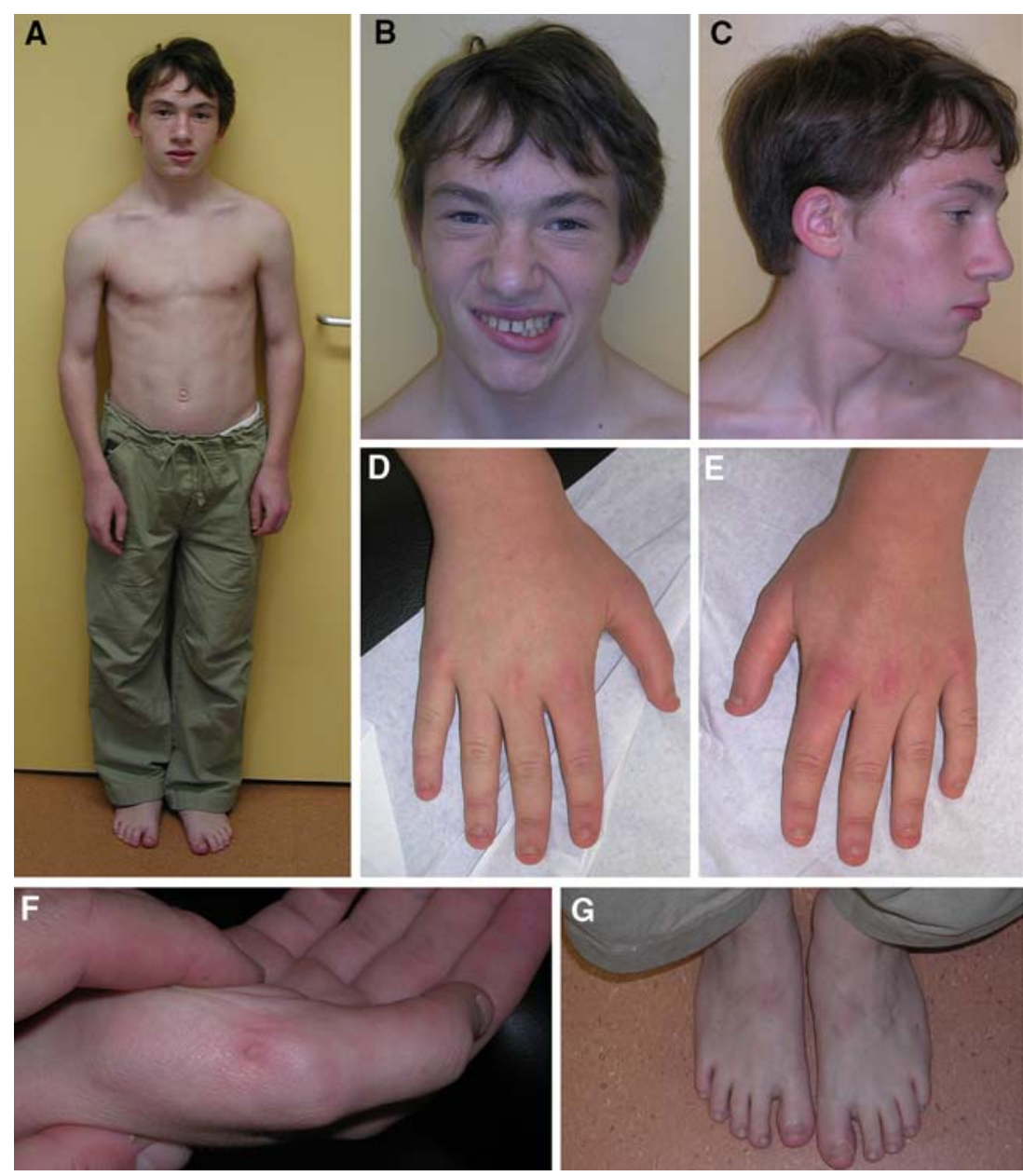

ectrodactyly. A set of nine uniquely sized MLPA probes, hybridising to genes in the $5 \mathrm{q} 35.1$ region ( $F G F 18$ and $F B X W 11$ ), was created according to a protocol provided by MRC-Holland (http:// www.mlpa.com/index.htm). Probe sequences are provided in Supplementary Table 1. Synthetic 5' or 3' halfprobes were obtained from Biolegio (Malden, The Netherlands). Hybridisation, ligation and amplification of the MLPA probes were performed as described previously (Koolen et al. 2004; Schouten et al. 2002). Amplification products were identified and quantified by capillary electrophoresis on an ABI 3730 genetic analyzer, using GeneMapper software (Applied Biosystems, Foster City, CA). Data were normalised as described by Koolen et al. (2004).

\section{Results}

A de novo copy-number gain at chromosome 5q35.1 was identified in the proband using a genome-wide $32 \mathrm{~K}$ BAC microarray. Figure 3 represents the chromosome
5 array CGH plot showing the $1.24 \mathrm{Mb}$ gain at $5 \mathrm{q} 35.1$ and the genes in the region. The centromeric breakpoint was within BAC clone CTD-2012P21 and RP11$768 \mathrm{O} 14$, and the telomeric breakpoint was within BAC clone CTD-2005E9 and CTD-2270L4. Based on the physical mapping positions as obtained from the May 2004 Freeze of the USCS Genome Browser, the size of the duplicated region was determined to be $1.24 \mathrm{Mb}$ (170.5-171.8 Mb). In addition, the aberration was not reported as large copy-number variation in the database of genomic variants (http://www.projects.tcag.ca/ variation/). Subsequent FISH analysis using intermediate BAC clones as probes yielded hybridisation signals on both chromosome 5 homologues. The signals on one of these homologs was subjectively larger, suggestive of a tandem microduplication of this region (data not shown). Array CGH and FISH experiments on parental samples did not reveal any aberration at 5q35.1, indicating a de novo anomaly in the patient. The duplication at 5q35.1 in the index patient was confirmed using specifically designed synthetic MLPA probes, hybridising to genes in the 5q35.1 locus (see 
Fig. 3 a Chromosome 5 array comparative genomic hybridisation (array CGH) plot showing the $1.24 \mathrm{Mb}$ duplication at 5q35.1 (arrow). Individual BAC clones are shown as dots ordered by $\mathrm{Mb}$ position from pter to qter (custom track UCSC Genome Browser, May 2004 Freeze). Hybridisation intensities are represented as $\log 2$ transformed and normalised test over reference intensity ratios $\left[\log _{2}(\mathrm{~T} / \mathrm{R})\right]$. b

Transcript map of the duplicated 5q35.1 genomic region. c Confirmation of array CGH data by multiplex ligation-dependent probe amplification (MLPA), using a specifically designed synthetic probe set containing nine probes corresponding to 5q35.1 (FGF18, FBXW11)

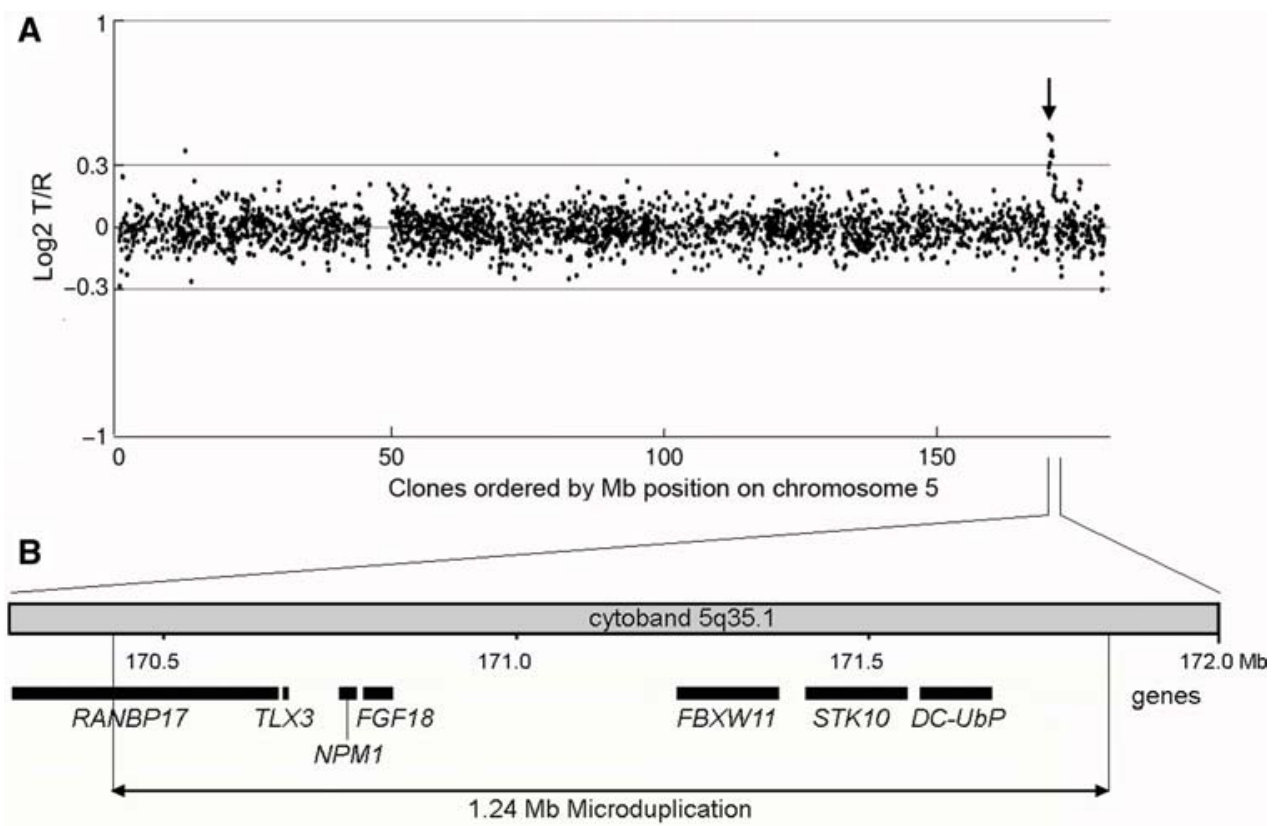

C

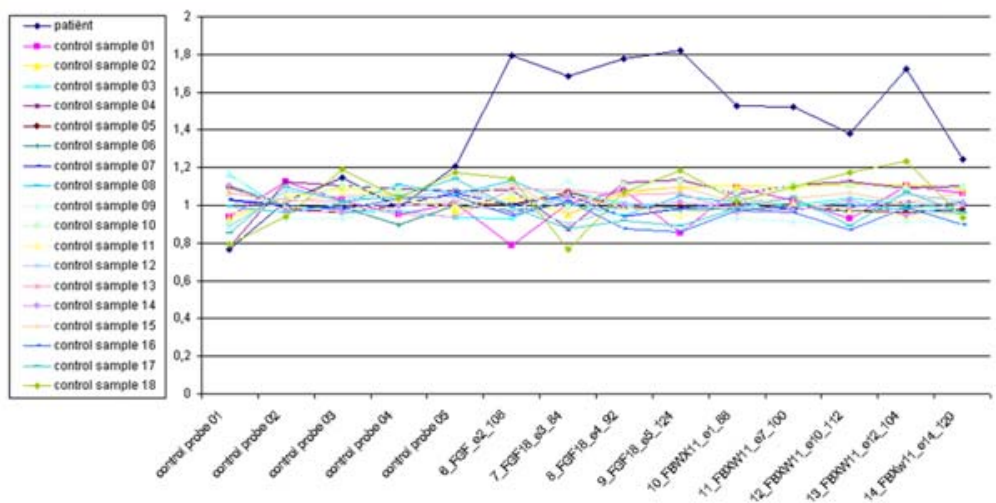

Fig. 3c). The same MLPA probe set was used to screen 31 additional patients diagnosed with HPE for copy number changes at 5q35.1; no additional anomalies were detected in these samples.

\section{Discussion}

In this study we describe the detection of a de novo $1.24 \mathrm{Mb}$ microduplication at 5q35.1 in a 19-year-old boy with HPE and preaxial polydactyly using a genome-wide tiling path resolution microarray. This finding suggests that one or more genes located within the duplicated region are sensitive to dosage alterations influencing brain development.

Clinical features commonly reported among 32 clinically well-described patients with microscopically visible duplications spanning cytoband 5q35.1 are low birth weight, developmental delay, mental retardation, microcephaly, down-turned palpebral fissures, hypertelorism, micrognathia, dysplastic ears and congenital heart defects (Groen et al. 1998; Lazjuk et al. 1985; Levy et al. 2002; Rodewald et al. 1980; Schinzel 2003; Schroeder et al. 1986). HPE was reported in two cases: a girl with a duplication of $5 \mathrm{q} 32 \rightarrow$ qter [46,XX,der(10)t(5;10)(q31.3;q26)] and a boy with a microscopically visible $5 \mathrm{q} 32->$ qter duplication and a $5 \mathrm{p} 15 \rightarrow$ pter deletion, due to an inversion [46,XY, $\operatorname{rec}(5)$, dup q, inv(5)(p15q32)] (Lazjuk et al. 1985; Schroeder et al. 1986). Preaxial polydactyly has been described in terminal 5q duplications in two patients, whereas in one patient a duplication of the terminal thumb phalanges was noted. The phenotype of HPE is known to be variable, even among family members carrying the same mutation (Dubourg et al. 2004). The latter is in concordance with the absence of HPE and/ or polydactyly in most patients with duplications encompassing the 5q35.1 region. 
Based on our findings, we screened for copy-number changes of $5 q 35.1$ in 31 patients with unexplained HPE using MLPA. However, MLPA analysis did not reveal additional aberrations in the 5q35.1 region.

Given that HPE and preaxial polydactyly are recurrent clinical findings in patients with terminal $5 \mathrm{q}$ duplication, the $1.24 \mathrm{Mb}$ duplication in our patient defines a $1.24 \mathrm{Mb}$ locus for HPE and preaxial polydactyly on human chromosome $5 \mathrm{q} 35.1$. The $1.24 \mathrm{Mb}$ duplicated region in our index patient encompassed at least seven genes: RANBP17, TLX3, NPM1, FGF18, $F B X W 11, S T K 10$, and $D C-U b P$. Several lines of evidence suggest that overexpression of the $F B X W 11$ gene is likely to be causative for HPE and limb malformation.

The $F B X W 11$ gene encodes the $\beta \mathrm{TRCP} 2$ protein, a F-box/WD40 repeat protein from the modular E3 ubiquitin protein ligase complex called SCFs (Skp1, Cdc53/Cull and F-box protein), which functions in phosphorylation-dependent ubiquitination (Kipreos and Pagano 2000). The Drosophila ortholog of $\beta$ TRCP, Slimb, is required for the proteolysis of the transcription factor cubitus interruptus (ci), the key mediator of hedgehog signaling (Ming et al. 1998; Villavicencio et al. 2000). $C i$ is the ortholog of the GLIKruppel gene family in vertebrates. Interestingly, lossof-function mutations in human GLI2 are associated with pituitary anomalies and HPE-like features (Roessler et al. 2003), whereas mutations in GLI3 can cause three distinct congenital syndromes: Greig cephalopolysyndactyly syndrome, Pallister-Hall syndrome, and postaxial polydactyly type A1 (Ming et al. 1998). Recently, it has been demonstrated that $\beta$ TRCP is directly involved in proteolytic processing of GLI3 in vertebrates (Wang and Li 2006). Thus, duplication of the $F B X W 11$ gene is likely to result in increased $\beta$ TRCP activity and consequently enhanced processing of GLI3 (Wang and Li 2006). Conversely, SHH is known to inhibit proteolytic processing of GLI transcription factors, and therefore acts to stimulate GLI-mediated transcription (te Welscher et al. 2002; Aza-Blanc et al. 1997). SHH is a crucial factor for the patterning of the ventral forebrain and is required for the separation of the primordial eye field and brain into two discrete hemispheres (Ming et al. 1998). Lossof-function mutations in the $\mathrm{SHH}$ gene are associated with the development of HPE (Belloni et al. 1996; Roessler et al. 1996) and polydactyly (Lettice et al. 2002). It thus seems that reduced GLI activity, due either to inactivating mutations of $S H H$ or $G L I$, or to overexpression of the $F B X W 11$ gene, contribute to the HPE and polydactyly phenotype. Additional evidence for the causative effect of duplication of the $F B X W 11$ gene is provided by the observation that duplications of the highly homologous $\beta T R C P 2$ gene at $10 \mathrm{q} 24.32$ are associated with split hand-split foot malformation (SHFM MIM 183600) (de Mollerat et al. 2003).

In summary, we define a novel $1.24 \mathrm{Mb}$ critical interval at 5q35.1 for HPE and preaxial polydactyly. We propose $F B X W 11$ as the most likely candidate gene for HPE. Further research is warranted to unravel the role of this candidate gene in brain and limb development and to determine the prevalence of copynumber gain in the 5q35.1 region among HPE patients.

Acknowledgements We thank the patient and his parents for their cooperation. We also thank M.H.A. Ruiterkamp-Versteeg for skilled technical assistance. This work was supported by grants from The Netherlands Organisation for Health Research and Development [ZonMW 907-00-058 (B.B.A.dV.); ZonMW 920-03-338 (D.A.K.); ZonMW 912-04-047 (H.G.B. \& J.A.V.)].

\section{References}

Aza-Blanc P, Ramirez-Weber FA, Laget MP, Schwartz C, Kornberg TB (1997) Proteolysis that is inhibited by hedgehog targets Cubitus interruptus protein to the nucleus and converts it to a repressor. Cell 89:1043-1053

Belloni E, Muenke M, Roessler E, Traverso G, Siegel-Bartelt J, Frumkin A, Mitchell HF, Donis-Keller H, Helms C, Hing AV, Heng HH, Koop B, Martindale D, Rommens JM, Tsui LC, Scherer SW (1996) Identification of Sonic hedgehog as a candidate gene responsible for holoprosencephaly. Nat Genet 14:353-356

Bendavid C, Haddad BR, Griffin A, Huizing M, Dubourg C, Gicquel I, Cavalli LR, Pasquier L, Long R, Ouspenskaia M, Odent S, Lacbawan F, David V, Muenke M (2006) Multicolor FISH and quantitative PCR can detect submicroscopic deletions in holoprosencephaly patients with a normal karyotype. J Med Genet (in press) Published Online First: 30 September 2005. doi:10.1136/jmg.2005.037176

De Vries BB, Pfundt R, Leisink M, Koolen DA, Vissers LE, Janssen IM, Reijmersdal S, Nillesen WM, Huys EH, Leeuw N, Smeets D, Sistermans EA, Feuth T, van RavenswaaijArts CM, van Kessel AG, Schoenmakers EF, Brunner HG, Veltman JA (2005) Diagnostic genome profiling in mental retardation. Am J Hum Genet 77:606-616

De Mollerat X, Gurrieri F, Morgan CT, Sangiorgi E, Everman DB, Gaspari P, Amiel J, Bamshad MJ, Lyle R, Blouin JL, Allanson JE, Le MB, Wilson M, Braverman NE, Radhakrishna U, ozier-Blanchet C, Abbott A, Elghouzzi V, Antonarakis S, Stevenson RE, Munnich A, Neri G, Schwartz CE (2003) A genomic rearrangement resulting in a tandem duplication is associated with split hand-split foot malformation 3 (SHFM3) at 10q24. Hum Mol Genet 12:1959-1971

Dubourg C, Lazaro L, Pasquier L, Bendavid C, Blayau M, Le DF, Durou MR, Odent S, David V (2004) Molecular screening of SHH, ZIC2, SIX3, and TGIF genes in patients with features of holoprosencephaly spectrum: mutation review and genotypephenotype correlations. Hum Mutat 24:43-51

Groen SE, Drewes JG, de Boer EG, Hoovers JM, Hennekam RC (1998) Repeated unbalanced offspring due to a familial translocation involving chromosomes 5 and 6 . Am J Med Genet 80:448-453 
Kipreos ET, Pagano M (2000) The F-box protein family. Genome Biol 1:3002.1-3002.7

Koolen DA, Nillesen WM, Versteeg MH, Merkx GF, Knoers NV, Kets M, Vermeer S, van Ravenswaaij CM, de Kovel CG, Brunner HG, Smeets D, De Vries BB, Sistermans EA (2004) Screening for subtelomeric rearrangements in 210 patients with unexplained mental retardation using multiplex ligation dependent probe amplification (MLPA). J Med Genet 41:892-899

Lazjuk GI, Lurie IW, Kirillova IA, Zaletajev DV, Gurevich DB, Shved IA, Ostrovskaya TI (1985) Partial trisomy 5q and partial monosomy $5 \mathrm{q}$ within the same family. Clin Genet 28:122-129

Lettice LA, Horikoshi T, Heaney SJ, van Baren MJ, van der Linde HC, Breedveld GJ, Joosse M, Akarsu N, Oostra BA, Endo N, Shibata M, Suzuki M, Takahashi E, Shinka T, Nakahori Y, Ayusawa D, Nakabayashi K, Scherer SW, Heutink P, Hill RE, Noji S (2002) Disruption of a longrange cis-acting regulator for Shh causes preaxial polydactyly. Proc Natl Acad Sci USA 99:7548-7553

Levy B, Dunn TM, Kern JH, Hirschhorn K, Kardon NB (2002) Delineation of the dup $5 \mathrm{q}$ phenotype by molecular cytogenetic analysis in a patient with dup5q/del 5p (cri du chat). Am J Med Genet 108:192-197

Ming JE, Roessler E, Muenke M (1998) Human developmental disorders and the Sonic hedgehog pathway. Mol Med Today 4:343-349

Rodewald A, Zankl M, Gley EO, Zang KD (1980) Partial trisomy 5q: three different phenotypes depending on different duplication segments. Hum Genet 55:191-198
Roessler E, Belloni E, Gaudenz K, Jay P, Berta P, Scherer SW, Tsui LC, Muenke M (1996) Mutations in the human Sonic Hedgehog gene cause holoprosencephaly. Nat Genet 14:357-360

Roessler E, Du YZ, Mullor JL, Casas E, Allen WP, GillessenKaesbach G, Roeder ER, Ming JE, Altaba A, Muenke M (2003) Loss-of-function mutations in the human GLI2 gene are associated with pituitary anomalies and holoprosencephalylike features. Proc Natl Acad Sci USA 100:13424-13429

Schinzel A (2003) Catalogue of unbalanced chromosome aberrations in Man, 2nd edn. de Gruyter, Berlin

Schouten JP, McElgunn CJ, Waaijer R, Zwijnenburg D, Diepvens F, Pals G (2002) Relative quantification of 40 nucleic acid sequences by multiplex ligation-dependent probe amplification. Nucleic Acids Res 30:e57

Schroeder HW Jr, Forbes S, Mack L, Davis S, Norwood TH (1986) Recombination aneusomy of chromosome 5 associated with multiple severe congenital malformations. Clin Genet 30:285-292

Te Welscher P, Zuniga A, Kuijper S, Drenth T, Goedemans HJ, Meijlink F, Zeller R (2002) Progression of vertebrate limb development through SHH-mediated counteraction of GLI3. Science 298:827-830

Villavicencio EH, Walterhouse DO, Iannaccone PM (2000) The sonic hedgehog-patched-gli pathway in human development and disease. Am J Hum Genet 67:1047-1054

Wallis D, Muenke M (2000) Mutations in holoprosencephaly. Hum Mutat 16:99-108

Wang B, Li Y (2006) Evidence for the direct involvement of \{beta\}TrCP in Gli3 protein processing. Proc Natl Acad Sci USA 103:33-38 